\section{Trakya Eğitim Dergisi}

Cilt 11, Sayı 2

Mayıs 2021, 889-899

Geliş Tarihi: 27.05.2020

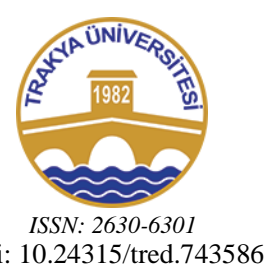

Doi: 10.24315/tred.743586

Araştırma Makalesi/
Trakya Journal of Education

Volume 11, Issue 2

May 2021, 889-899

Yayına Kabul Tarihi:04.03.2021

Research Article

\title{
ÖZEL YETENEKLILERIN TANILANMASINDA SINIF DÜZEYLERININ UZMAN GÖRÜŞLERINE GÖRE KARŞILAŞTIRILMASI
}

\section{COMPARISION OF GRADE LEVELS ON IDENTIFICATION OF GIFTED STUDENTS ACCORDING TO EXPERTS' OPINIONS}

\begin{abstract}
Abdullah EKER ${ }^{1}$, Hakan Sarı ${ }^{2}$
Öz: Bilim Sanat Merkezleri (BİLSEM), Milli Eğitim Abstract: Science and Art Centers (SAC) are the unique formal Bakanlığ1 tarafından 1993 yılında kurulmaya başlanan, institutions about gifted students in Turkey which were founded ülkemizde özel yetenekli çocukların özel eğitim by the Ministry of National Education. Since 1993 SACs are gereksinimlerine yönelik destek eğitim hizmetleri veren en founded as an after school support centers enrolled in primary yaygın eğitim kurumlarıdır. BILLSEMLER; İlköğretim ve and secondary schools for the special needs of gifted students. Ortaöğretim çağındaki öğrencilerin özel yeteneklerini The mission of these institutions is to help those children to geliştirerek bilimsel düşünce ve davranışlarla estetik discover their individual talents and optimize their use of değerleri birleştiren, üretken, problem çözen bireyler haline capabilities. In SACs, gifted children should attend groups with gelmelerini özel eğitim aktiviteleri yoluyla sağlayan eğitim their homogenous talented peers to be able to study with special kurumlarıdır. BİLSEMLER de birebir ve proje tabanlı eğitim and professional teachers also they are studying one-by-one with verilmektedir. Türkiye'de günümüzde yaklaşık olarak 180 using project based individualized programs. There are about BİLSEM bulunmaktadır. BİLSEM'e öğrenci kabulü için 180 SACs in Turkey (approximately one center in one province). zekâ ve yeteneğin tanılanması konusunda hangi yaşın daha There is a debate among Turkish professionals which indicate uygun olduğu, erken tanılama için hangi yaştan başlanması some concerns about whether the students' identification and gerektiği ve öğrencinin tanılama ölçeklerini uygulama assessment should start from the second grades or from the becerisi düzeyi uzmanlar arasında yoğun bir şekilde fourth grades because last year, the Turkish Ministry of National tartışılmaktadır. MEB önce 4. sınıf düzeyinde tanılama Education decided that identifying age should start from the yaparken bu seneki eğitim döneminde tanılama düzeyini 4. second grade instead of fourth grade. There is not any study sınıftan 2. sınıfa çekmiştir. Daha sonra da 1. Sinıf showing the scientific necessaries on this issue to be able to düzeyinden 3. Sinıf düzeyine kadar olan esnek bir yelpazede solve that debate in the minds. Therefore, the aims this research tanılama çalışmaları yürütülmeye başlanmıştır. Ancak is; 1) to explore the perceptions of the professional experts who tanılama yaşındaki yapılan değişikliklerin tanılama are responsible for identifying and assessing special talented üzerindeki etkisine ilişkin ülkemizde henüz bilimsel bir children and work in National Guidance and Research Center çalışma bulunmamaktadır. Bu nedenle bu çalışma da farklı (GRC). GRCs are the formal psychological identifying and iki sınıf düzeyindeki tanılamanın avantajları ve sınırlılıkları; counseling centers of Turkish education system. The tanılama çalışmalarını bizzat yapan ve tanılama ölçeklerinde professionals in GRCs are responsible for using and evaluating uzman olan Rehberlik ve Araştırma Merkezlerindeki (RAM) psychological and standardized tests for the identification and uzmanların görüşlerine göre karşılaştırmalı biçimde assessment issues in Turkey and 2) to light the researchers who değerlendirilmeye çalışılmıştır. Çalışma da araştırmacılar would want to do further researches on that issue. In the study, a tarafından geliştirilen yarı yapılandırılmış görüşme formu semi-structured interview form -developed by the researcherskullanılmıştır. Toplam 30 RAM uzmanının görüşüne was used as the data collection tool and descriptive qualitative başvurulmuş ve sonuçlar nitel araştırma yöntemleri ile analiz analysis technique was used for the analysis of the data. For this edilmiştir. study 30 professionals were selected from GRC's in Turkey.

Anahtar Kelimeler: Özel Yetenek, Özel Yeteneklileri Key words: Giftedness, Gifted Identification, Identification Tanılama, Tanılama Yaşı, RAM, BİLSEM Age, SAC, GRC
\end{abstract}

\footnotetext{
${ }^{1}$ Dr. Öğr. Üyesi, Kilis 7 Aralık Üniversitesi, Eğitim Fakültesi, Özel Eğitim Bölümü, abdullah.eker@kilis.edu.tr, ORCID:00000002-6409-7732

${ }^{2}$ Prof, Dr., Necmettin Erbakan Üniversitesi, Eğitim Fakültesi, Özel Eğitim Bölümü, hsari@konya.edu.tr, ORCID: 0000-00034528-8936
} 
Bu makaleye atıf vermek için:

Eker, A. ve Sarı, H. (2021). Özel Yeteneklilerin Tanılanmasında Sınıf Düzeylerinin Uzman Görüşlerine göre Karşılaştırılması, Trakya Ĕgitim Dergisi, 11(2), 889-899

Cite this article as:

Eker, A., \& Sarı, H. (2021). Comparision of grade levels on identification of gifted students according to experts' opinions, Trakya Journal of Education, 11(2), 889-899

\section{EXTENDED ABSTRACT}

\section{Introduction}

Gifted and talented students have different learning needs from those of their age peers and therefore need special educational planning to support them in developing their potential (Renzulli, 2004: 13). The main purpose in identfying gifted students must be related to a special education or counseling program. The identification system should be able to determine individual characteristics of the students and must overlap with the contents of the training programs for the students (Sak, 2014)

These study is about assessing and exploring «when» discussion in Turkey. One of the most important principles in special education is early age. It is thought that early recognition is important to achieve the highest level of satisfaction and development of the child. When it is desired to provide students with optimal development opportunities, it is critical to identify and educate gifted children at an early age as a critical issue. Early identification of this potential however, is important so that students receive the educational opportunities that will allow this potential to be fulfilled.

The Guidance Research Centers (GRCs) are main associations in gifted identification process. The professionals in GRCs are responsible for using and evaluating psychological and standardized tests for the identification and assessment issues in Turkey and Science and Art Centers are the unique formal institutions in Turkey which were founded by the Ministry of National Education since 2006 as an intervention challenge for thae special needs of gifted students. In SACs, gifted children should attend groups with their homogenous talented peers to be able to study with special and professional teachers also they are studying one-by-one with using project based individualized programs. There are about 180 Science and Art Center (SAC) in Turkey (approximately one center in one province)

There is a debate among Turkish professionals which indicate some concerns about whether the students' identification and assessment should start from the second grades or from the fourth grades because last year, the Turkish Ministry of National Education decided that identifying age should start from the first grade instead of third grade. So as; the aims this research is to explore the perceptions of the professional experts who are responsible for identifying and assessing special talented children and work in National Guidance and Research Centers (GRCs). GRCs are the formal psychological identifying and counseling centers of Turkish education system and to determine the perceptions of the experts who work in GRCs on whether we should identify the students from grade two or from grade four to be able to get access to Science and Art Center for getting special support services for the identified students.

\section{Method}

This research was conducted with qualitative research methods. The purpose of qualitative research is to examine the sample more throughly. Qualitative research designs are often flexible and dynamic. The main characteristic of qualitative research is to specify the perspective of the interviewee. For this reason, it is essential to understand the emotions and thoughts of the participants and obtain deeper knowledge (Kus, 2009:11). Therefore, this method was used in this study to determine the opinions and opinions of the experts. In the study, a semi-structured interview form -developed by the researchers- was used as the data collection tool and descriptive qualitative analysis technique was used for the analysis of the data. For this study 30 professionals were selected from GRC's in Turkey.

\section{Results}

According to the findings of the research, among the experts who carry out the process of identifying Specially Talented in Guidance Research Centers, those who think that the decision to start the identification age from the 1st grade is positive and those who think it is negative are very close to each other. However, when the content was evaluated in depth, it was observed that the experts liked the identification tools that were introduced with the age of identification.

In addition to this: experts generally think that the disadvantages of 1st grade level identification are partially controlled with the additional measures taken for the level of identification age in the scale and application procedures. However, based on the research findings, it can be said that the experts agree 
that it would be beneficial to not limit the identification studies to the 1st and 2nd grades and to continue the identification studies in the 3rd and 4th grades considering the limitations. According to experts, the most important contribution is the early identification age to discover students with special talent in the artistic field and to support them early in their talent areas.

Experts expressed a very limited opinion on the contribution of the early identification age to the applied program. They stated that the reason for this situation was the lack of communication with the applied program and the opportunity to observe the program outputs. There are disadvantages of lowering the age of identification in four different dimensions. According to expert opinions; In terms of students' ability to express themselves, students' level of readiness for the identification application, students' understanding of the application instructions, and the student's level of tolerance to the implementation period, difficulties are encountered in early-age identification practices.

According to the majority of experts, it is thought that the newly introduced domestic and national intelligence scales increase the success of the process of identifying special talent in our country and provide ease of application. Experts stated that it would be beneficial to reduce the learning effect in the repetitive application of the ASIS scale.

\section{Conclusion and Discussion}

According to research findings, it was observed that the experts who conducted the process of identifying gifted talents in the Guidance Research Centers (GRC) found that the decision to withdraw the age of identification to the first grade level was positive and that the new applied scale was favorable. This is in line with the 'early identification' principle, which has become one of the most basic principles of special education, and past research conducted on the field of early recognition.

Experts believe that as a majority, the disadvantages of first-class level identification are controlled by additional measures taken on the scale and in implementation procedures. Experts have stated that the age of identification does not have sufficient experience and observation on the effects on the program. This situation coincides with the findings of the research conducted by Sak (2015), which shows that there is a discrepancy between the identification scales GRC and the applied program. Accordingly, the lack of cooperation and communication between specialists and the developers of the SAC program can be mentioned.

\section{GíRiș}

Özel eğitimde en önemli ilkelerden biri erkenlik ilkesidir (Seçer ve Sarı, 2006). Özel yeteneklilerin eğitiminde de çocuğun en üst düzeyde yeteneğinin gelişimini desteklemek için erken tanılamanın önemli olduğu düşünülmektedir. Dolayısıyla özel yetenekli öğrencilere yüksek düzeyde gelişim firsatı sağlamak için erken yaşlarda tanılanmaları ve destek eğim almaları gereği önemli bir konu olarak karşımıza çıkmaktadır (Heller ve Schofield, 2008: 94). Moore (1992: 424) ise bir çocuktaki mevcut yetenekler ne kadar erken fark edilirse, o ölçüde sahip olduğu kapasitenin körelmesine etki edecek faktörlerden uzak kalabileceğini ve yeteneklerini geliştirilmesi için uygun ortam sağlanabileceğini belirtmiştir.

\section{Özel Yeteneklilerin Eğitiminde Tanılama}

Özel yetenekli öğrencileri tanılama; zekâ, yaratıcılık ve başarı gibi bireysel özelliklere ilişkin bilgilerin toplandığı ve bu bilgiler doğrultusunda öğrencilerin zihinsel kapasiteleri veya potansiyelleri hakkında kararların alındığı bir süreci kapsar (Eker, Kurnaz ve Sarı, 2018: 16). Bu süreçte öğrenci ile ilgili olarak toplanan bilgilerin detaylı, doğru ve güvenilir olması; bilgi toplama araçlarının çeşitliliği ve farklı disiplinlerden uzmanların tanılama sürecine katkıda bulunması tanılamanın kalitesini artırır (Sak, 2012: 244)

Bununla birlikte özel yetenekli öğrencilerin nasıl ve hangi araçlarla tanılanacağı konusunda araştırmacılar ve eğitimciler arasında birçok farklı görüş ortaya atılmıştır ve özel yeteneklilerin tanılanması ile ilgili ülkemizde ve dünyada birçok güncel sorun bulunmaktadır. Bu bağlamda Heller ve Schofield (2008: 99) özel yeteneklilerin tanılanması ile ilgili olarak " $4 \mathrm{n}$ " şeklinde tanımladıkları sorularının cevaplanması gerektiğini belirtmişlerdir. Buna göre özel yeteneklilerin eğitiminde uygulanacak bir tanılama süreci aşağıdaki sorulara yanıt vermelidir (Heller ve Schofield2008: 100):

1) Ne tanılanmalıdır? Özel yetenek göstergeleri olarak ne tür özellikler ve beceriler ölçülmelidir? 2) Tanılama neden yapılmalıdır? Özel yetenekli öğrencileri tanılamanın amaçları veya gerekçeleri 
nelerdir? 3) Özel yetenekli öğrenciler nasıl tanılanmalıdır? Özel yetenekli öğrencileri tanılamak için ne tür ölçümler, yöntemler ve araçlar kullanılmalıdır? 4) Özel yetenekli öğrenciler ne zaman tanılanmalıdır? Gelişim sürecinin ve eğitim kademelerinin hangi dönemleri tanılama için uygundur?

Sonuç olarak günümüzde dünyada özel yeteneği tanılama ile ilgili olarak farklı politika, model ve stratejiler bulunmaktadır. Bazı tanılama süreçleri sadece zekâ puanı üzerinde dururken, bazıları -özellikle son yıllarda- çok boyutlu değerlendirmenin avantajlarından ve öneminden bahsetmektedir (Eker, Kurnaz ve Sarı, 2018: 17). Ancak ideal bir tanılama sisteminden bahsetmek de mümkün değildir. Bunun çok çeşitli nedenleri bulunmaktadır. Örneğin öğrenciler, birbirlerinden farklı düzeylerde farklı yeteneklere sahiptir (Clark, 1997, s.54). Standardize zekâ testlerinin, akademik ve genel yetenek haricindeki yetenek alanlarını ölçme bakımından sınılılıkları vardır (Tucker ve Hafenstein, 1997). Bu araştırma ile ise, ülkemizde özel yeteneklilerin tanılanmasında ölçüt alınacak tanılama yaşına yönelik uzmanlara ve araştırmacılara bilimsel kanıt temelli destek sağlanması hedeflenmiştir.

\section{Rehberlik ve Araştırma Merkezleri (RAM)}

Özel Yeteneklileri tanılama ve yerleştirme uygulamalarından sorumlu olan Rehberlik Araştırma Merkezleri (RAM) bu sürecin adeta kilit noktası durumundadırlar. Milli Eğitim Bakanlığı Özel Eğitim Hizmetleri Yönetmeliği'nde belirlenen mevzuatla ilgili tüm unsurları pratikte uygulamaya, dönüştürme ve yürütme noktaları RAM'lardır (MEB, 2018). Milli Eğitim Bakanlığı 2006 yönetmeliği ve 2018 BİLSEM tanılama yönergesine göre Rehberlik ve Araştırma Merkezleri: "Bölgesindeki özel yetenekli bireylerin tanılanması ve bu bireylere yönelik destek eğitim hizmetleri ve rehberlik ve psikolojik danışma hizmetlerini yürütülmesini sağlamakla yükümlüdür” denilmektedir. $\mathrm{Bu}$ nedenle de RAM'lardaki uygulamaları ve çalışanların görüşlerini alan araştırmalar bu açıdan ayrıca önem kazanmaktadır.

\section{Türkiye'de Bilim ve Sanat Merkezleri (BÍLSEM)}

Bilim Sanat Merkezleri (BİLSEM), Milli Eğitim Bakanlığı tarafından 1993 yılında kurulmaya başlanan, ülkemizde özel yetenekli çocukların özel eğitim gereksinimlerine yönelik destek eğitim hizmetleri veren en yaygın eğitim kurumlarıdır. BİLSEMLER; İlköğretim ve Ortaöğretim çağındaki öğrencilerin özel yeteneklerini geliştirerek bilimsel düşünce ve davranışlarla estetik değerleri birleştiren, üretken, problem çözen bireyler haline gelmelerini özel eğitim aktiviteleri yoluyla sağlayan eğitim kurumlarıdır. BILLSEMLER de birebir ve proje tabanlı eğitim verilmektedir. Türkiye'de günümüzde toplam 113 Bilsem bulunmaktadır. Bilim ve sanat merkezleri (BİLSEM) özel yetenekli öğrencilerin eğitimine ilişkin ülkemize has bir modeldir (Baykoç Dönmez, 2014: 14). Günümüzde özel yetenekli öğrenciler için ülkemizde uygulanabilecek pek çok model tartışılmaktadır. Bununla birlikte ülkemizin bilim ve sanat merkezlerindeki deneyimleri diğer model uygulamaları için çıkış noktası oluşturmaktadır (Sar1, 2003: 47). Bu nedenle bilim ve sanat merkezlerinin nitelikler ve etkililikleri, tanılama ve yerleştirmenin program hedefleri ile uyumluluğu gibi konulara yönelik bilimsel araştırmalara gereksinim duyulduğu söylenebilir. Tanılama yaşında yapılan değişikliklere yönelik ise ülkemizde yapılmış bir araştırmaya rastlanmamıştır. Bu çalışma ile de bizzat tanılama çalışmalarını yürüten uzmanların özellikle bireysel tanılama aşamasına yönelik görüşlerine dayalı olarak özel yetenekli bireylerin tanılanması sürecindeki değişimler değerlendirilmeye çalışılmıştır.

\section{YÖNTEM}

Bu bölümde bu araştırmanın deseni, çalışma grubu, veri toplama araçları ve veri analizleri ile ilgili bilgiler sunulmaktadir.

\section{Araştırma Modeli}

$\mathrm{Bu}$ araştırma nitel araştırma yöntemlerinden 'Yarı Yapılandırılmış Görüşme Tekniği' ile gerçekleştirilmiştir. Nitel araştırmada amaç, örneklemi daha kapsamlı incelemektir. Nitel araştırma desenleri genellikle esnek ve dinamiktir. Tümevarım mantığına göre araştırmanın ilk aşamasında çıkan bir durum, araştırmanın sonraki aşamalarını da etkileyebilmektedir. (Büyüköztürk, Kılıç Çakmak, Akgün, Karadeniz ve Demirel, 2010: 19).

Nitel araştırmalarda temel özellik, görüşülen kişilerin bakış açılarını belirlemektir. Bu nedenle, katılımcıların duygu ve düşüncelerini anlayarak daha derin bilgi edinmek esastır (Kuş, 2009: 11). 
Dolayısıyla, uzmanların düşünce ve görüşlerini belirlemek ve karş1lıklı görüşme ile daha detaylı ve nitelikli bilgi edinebilmek amacıyla araştırmada bu yöntem kullanılmıştır.

\section{Veri Toplama Aracı ve Uygulama Süreci}

Araştırmaya ilişkin alanyazın taraması ve saha incelemesi çalışmalarından sonra amacına uygun olarak araştırmacılar tarafından yarı yapılandırılmış görüşme formu hazırlanmıştır (Bkz. Ek.1). Görüşme formu hazırlanırken üç alan uzmanının ve Ram'larda görev yapan iki eğitsel tanılama uzmanının dönüt ve değerlendirmeleri ışı̆̆ında form revize edilerek son şeklini almıştır. Geliştirilen uzman görüşme formunda altı adet açık uçlu soru bulunmaktadır. Sorular hedefe ilişkin olarak belirli konularda uzman görüşlerini elde etmeye yönelik olarak hazırlanmıştır. Bu sorular kapsamında uzmanların başvurulan görüşleri ile öncelikli olarak (1.-4. sorular) 1. sınıf ve 3. sınıf düzeylerinde ölçeğin uygulanması sırasında gözlemlenen yararların ve karşılaşılan güçlüklerin neler olduğunun tespit edilmesi hedeflenmiştir. İkincil hedef olarak ise, (5. ve 6. sorular)tanılama araçlarının güvenirliğinin ve uzman anketörlerin uygulama yeterliğinin genel olarak uzman görüşlerine dayalı olarak değerlendirilmesi amaçlanmıştır. Uygulama röportaj tekniği ile geliştirilen yarı yapılandırılmış görüşme formundaki soruların araştırmacı tarafından bizzat sözel olarak sorulması ve cevapların daha sonra transkriptizasyonu yapılmak üzere ses kaydının alınması yöntemiyle yapılmıştır.

\section{Çalışma Grubu}

$\mathrm{Bu}$ araştırmanın katılımcıları Ankara, Konya, Kayseri ve Isparta ili sınırlarındaki Rehberlik ve Araştırma merkezlerine görev yapan 30 uzmandan oluşmaktadır. Uzmanların 21'i erkek ve 9'u kadın ve 22'si lisansüstü mezunu ve 8'i lisans mezunudur. Araştırmaya katılanlara araştırmanın amacı açıklanmıştır. Araştırma için ilgili makamlardan izinler alınmış ve araştırma için geliştirilen yarı yapılandırılmış görüşme formları araştırmaya katılmak istediğini sözel olarak ifade eden katılımcılara uygulanmıştır. Örneklem grubuna ilişkin betimsel bilgiler Tablo l'de gösterilmektedir.

Tablo 1.

Araştırmaya katılan uzmanlarla ilgili frekans dağılımları

\begin{tabular}{lcccc}
\hline \multirow{2}{*}{ Eğitim Düzeyi } & \multicolumn{2}{c}{ Cinsiyet } & f & $\%$ \\
\cline { 2 - 4 } & Erkek & Kadın & & \\
\hline Lisansüstü mezunu & 15 & 7 & 22 & 73 \\
\hline Lisans Mezunu & 6 & 2 & 8 & 27 \\
\hline Toplam & 21 & 9 & 30 & 100 \\
\hline
\end{tabular}

\section{Verilerin Analizi}

Yar1 yapılandırılmış görüşme formuyla toplanan verilerin çözümlemesi (transkriptleri) yapılmış ve sonra anahtar sözcükler belirlenerek veriler kodlanmıştır. Daha sonra kodlanan anahtar sözcükler çerçevesinde sistematik içerik analizi yapılmıştır. Araştırmanın amacına uygun olarak geçen anahtar kavramlar transkriptlerin sağında yer alan boşluklara not edilip bu notlar tek tek incelenerek 'Bulgular' bölümündeki gibi temalar oluşturulmuştur. Katılımc1 uzmanlar ise $U 1, U 2, U 3, \ldots U n$ şeklinde numaralandırılarak değerlendirilmiştir. Bulgulara yönelik örnek olarak verilen görüşme kesitlerinde yine uzmanlar için aynı gösterim yöntemi kullanılmıştır.

\section{BULGULAR}

Bu bölümde araştırmanın amacı doğrultusunda toplanan veriler analiz edilerek elde edilen veriler üç ayrı başlık altında sunulmuştur.

\section{Birinci Sınıf ve Üçüncü Sınıf Düzeyinde Tanılamanın Uzman Görüşlerine Göre Karşılaştırması}

İlk soru için yapılan değerlendirmelere göre uzmanların yarıdan az fazla bir kısmı (16: \%53) tanılama düzeyinin birinci sınıfa çekilmesinin doğru bir müdahale olduğunu ve yararlı bulduklarını 
belirtmişlerdir. Bu görüştekilerin tamamının erken tanılamanın yeteneğin gelişimine olan katkısına vurgu yaptıkları görülmektedir. Diğerleri ise (14: \%47) çoğunlukla üçüncü sınıf düzeyinde tanılamanın, uygulama güvenirliği açısından daha avantajlı olduğunu gerekçe göstererek birinci sınıfa çekilmesinin olumsuz bir müdahale olduğunu düşündüklerini belirtmişlerdir. Uzman görüşlerinden bazıları kendi ifadeleriyle kesitler halinde aşağıda sunulmaktadır:

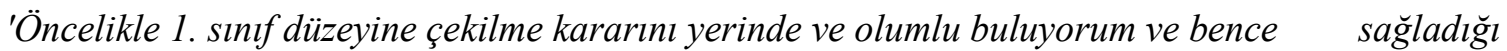
en büyük yarar ögrencinin yeteneğinin erken keşfedilip erken yönlendirilmesiyle öğrencinin potansiyelinin daha üst düzey ortaya çımasına katkı sağlayacaktır' (U1).

'1. sinıf düzeyine indirme çok gereksinim duyulan bir karardl. Ölçekte düzeyle ilgili gerekli uyarlamalar yapılarak ve tüm risk faktörleri gözden geçirilerek planlı bir şekilde yeni uygulamaya geçildi' (U5).

'1. sınıf düzeyine indirilmesini özellikle sözel yeteneklerin tanılanması yeni ölçekte $\quad$ yetersiz. olduğu için olumlu bulmuyorum. Çok radikal oldu. Belki bir düzey indirilebilirdi. İki düzey indirilmesinin dezavantajlarının daha çok olduğunu düşünüyorum' (U17).

\section{Birinci Sınıf Düzeyinde Tanılamanın Üçüncü Sınıfa Göre Avantajlarının Değerlendirilmesi}

$\mathrm{Bu}$ soruya verilen cevaplar için içerik analizi yapıldığında beş temel anahtar kod oluştuğu görülmüştür. Buna göre uzmanların birinci sınıf düzeyinde tanılamanın üçüncü sınıf düzeyine oranla avantajlarına ilişkin belirttikleri görüşleri içerik analizine göre beş farklı başlıkta ele alınmıştır.

\section{Yetenek gelişimine katkısı}

Uzmanların çoğunluğu (19: \%62) birinci sınıf düzeyinde tanılama yaparak yeteneğin erken tanılanması sayesinde daha iyi geliştirilebileceğine ilişkin olumlu görüş belirtmişlerdir. Bazı uzmanlar yeteneklerin çok küçük yaşlarda yeterince gözlemlenemeyeceğini ve henüz ortaya çıkmamış olabileceğini belirtse de, tanılanabilen yetenekler için erken müdahalenin yararlı olduğunu da belirtmişlerdir. Uzman görüşlerinden bazıları kendi ifadeleriyle kesitler halinde aşă̆ıda sunulmaktadır:

'Tabiri caizse erken teşhis hayat kurtarır sözü gibi erken yönlendirme potansiyelin ortaya çıkması için çok önemli olduğunu düşünüyorum. A ̆gaç yaşken eğilir sözü de erken yönelmenin önemini de ifade ediyor mesela' (U3).

'Öğrencilere en uygun gelişim firsatı sağlanmak istendiğinde, erken yaşlarda yetenekli çocukları tanılama ve eğitme kritik bir konu olarak karşımıza çıkmaktadır. Bu bağlamda sürekli tanılama mekanizmalarının geliştirilmesi gayretinde olunması ülkemiz için olumlu bir durumdur' (U6).

'Erken yaşta yeteneğinin farkına varan ve o alanda destek eğitimi alan öğrenci ile geç yaşta yeteneğine yönelen ögrenci arasında ortaya konulan performans açısından çok yüksek düzeyde fark olduğunu düşünüyorum' (U7).

\section{Sanatsal yetenekler için katkısı}

Uzmanlar birinci sınıf düzeyinde tanılamanın en çok (27: \%90) sanatsal yeteneklerin gelişimi için yararlı olabileceğini belirtmişlerdir. Birinci sınıf düzeyinde tanılamanın yeteneklerin daha üst düzey başarıya dönüşebilmesi için yararlı olduğuna inandıklarını belirten uzmanların, sanatsal yeteneklerin keşfedilmesi ve gelişmesi için olası yararını ise özellikle vurguladıkları görülmektedir. Bilişsel yeteneklerin gelişimi için birinci sınıfta tanılamanın etkili olamayacağını savunan bazı uzmanlarında, sanatsal yeteneklerin gelişimi için yararlı olabileceğini belirttikleri görülmektedir. Uzman görüşlerinden bazıları kendi ifadeleriyle kesitler halinde aşağıda sunulmaktadır:

'Özellikle sıra dışı sanatsal yeteneklerin bilişsel yeteneklere göre kendini daha erken gösterdiğine inanıyorum. Örneğin 4 yaşında imparatora konser veren Mozart gibi.'(U8)

'Sanat ve spor yeteneği için tanılama yaşının daha kritik öneme sahip olduğunu düşünüyorum. Örneğin buz pateni balerinleri için tanılamaya ve eğitime 4 yaşında başlanır. 7 yaşına gelen bir çocuk için artık çok geç demektir.' (U2)

\section{Yerleştirilen programın etkililiğine katkısı}


Uzmanlar birinci sınıf düzeyinde tanılamanın ağırlıklı olarak (23: \%76) tanılama ölçeklerinde ve tanılama yaşındaki değişimlerin programa etkisi ile ilgili herhangi bir fikir sahibi olmadıklarını belirttiler. $\mathrm{Bu}$ durumun; RAM'lardaki tanılama anketörleri ve BİLSEM öğretmenleri arasındaki işbirliği eksikliğinden ya da program etkilerine dönük herhangi bir geri bildirim sistemi olmamasından kaynaklanabileceği yorumu yapılabilir. Uzmanların belirttikleri bir diğer neden ise programa öğrenciler kısa zaman önce yerleştikleri için program etkilerini gözlemleyecek yeterli uygulamanın henüz olmamasıdır. Uzman görüşlerinden bazıları kendi ifadeleriyle kesitler halinde aşağıda sunulmaktadır:

'Açıkçası bu değişimin program üzerindeki etkilerine ilişsin bir şey söylemem doğru olmaz. Çünkü bu konuda BILLSEM'lerle herhangi bir görüşmem olmadı.' (U11)

'1. sınıfta tanıladı̆̆ımız ögrenciler Bilsem deki eğitimlerine bir ay kadar önce başladılar. Bu nedenle program etkileri ile ilgili belki ancak birkaç yll sonra konuşulabilir. Gerçi program etkilerini karşılaştıracak herhangi bilimsel bir ölçeğinde geliştirildiğini duymadım.' (U29)

\section{Ebeveyn beklentilerinin karşılanması için katkısı}

Uzmanların yarıya yakın bir kısmı (14: \%47) birinci sınıf düzeyinde tanılamanın ebeveyn beklentileri ile ilişkisi olduğunu belirtmişlerdir. Buna göre daha erken düzey tanılama zaten ailelerin kurumlarından talep ettiği bir istekti ve yapılan düzenlemelerde veli beklentilerine de daha iyi cevap verme olanağ doğmuştur ve veliler anasınıfından itibaren çocuğunun özel yetenekli olduğuna inanıyorsa yardım ve destek arayışına girmektedirler. Bu bağlamda ülkemizdeki özel yetenekli bireylerin ebeveynlerinin beklentileri ve çocuklarına dönük algıları gelecekte daha kapsamlı araştırmalarla ele alınabilir. Uzman görüşlerinden ikisi kendi ifadeleriyle kesitler halinde aşağıda sunulmaktadır:

'Birinci sınıfta tanılamanın bir diğer yararının da ailelerin beklentilerine çözüm üretmesi olduğunu düşünüyorum. Çocuğunun yetenekli olduğunu düşünen aileler sık sık kuruma çocuklarıyla gelip tanılama yapmamız ve destek eğitimlerine erken başlanılması için taleplerde bulunuyorlardı.' (U1)

'Bu yeni düzenlemeden ailelerde daha memnunlar. Zaten böyle bir kamuoyu talebi vardl. Önceki yıllarda kurumumuza gelerek üçüncü sınıf düzeyine kadar bir müdahale olmamasından yakınan ebeveynler ve STK temsilcileriyle karşılaştım.'(U16)

\section{Öğrenci beklentilerinin karşılanması için katkısı}

Uzmanların az bir kısmının da birinci sınıf düzeyinde tanılamanın (7: \%23) öğrenci beklentilerine dönük yararlarına değindikleri görülmektedir. Buna göre; tanılamayı birinci sınıf düzeyine çekme kararı; özellikle bazı yetenek alanlarında akranlarına göre sıra dışı performans sergileyen küçük yaştaki öğrencilerden gelen destek eğitim taleplerine karşılık vermesi açısından yararlı olmuştur. Bu konuya değinen uzman sayısının azlığı, öğrencilerin büyük çoğunluğunda küçük yaşlarda kendine dönük beklenti ve kariyer kaygısının henüz gelişmemiş olması ile açıklanabilir. Uzman görüşlerinden kendi ifadeleriyle bir kesit aşağıda sunulmaktadır:

'Daha önceki yıllarda "bana yeteneğimi destekleyen bir çözüm bulun" diye kapımıza dayanan öğrenciler oldu. Tabi bu ögrencilerin çok erken yaşlardan itibaren yeteneğe dönük aile desteği ve yönlendirmesine sahip oldukların belirtmem gerekir' (U 30)

\section{Birinci Sınıf Düzeyinde Tanılamanın Üçüncü Sınıf Düzeyinde Tanılamaya Oranla Dezavantajları}

Uzmanların büyük bir çoğunluğu (26: \%86) çeşitli durumlar açısından birinci sınıf düzeyi tanılamanın bazı dezavantajlarını ve sınırlılıklarını belirtmişlerdir. Dezavantaj ve sınırlılıklara ilişkin görüş belirten uzman sayısının; yararları ve avantajları belirten uzman sayısından daha fazla olduğunu görmekteyiz. Bununla birlikte birinci sınıf düzeyinde tanılamaya başlanmasının doğru bir karar olduğunu belirten 16 uzman (\%53) bu dezavantajların bazı ek önlemlerle minimize edilmesi sayesinde avantajların dezavantajlardan çok daha fazla olduğunu vurgulamışlardır.

Uzmanlar tarafından belirtilen bu ek önlemler:

a) Yeni ve daha güncel olan bir ölçeğe geçilmiş olmas1,

b) Yeni ölçeğin sözel olmayan bir ölçek olması,

c) Uygulama süresinin çok daha kısa olması,

d) Yönerge açıklığının ve basitliğinin düzeye göre ayarlanmış olması,

e) Yönergelerin gösterime dayalı hale getirilmiş olması ve 
f) Öğrencilere 2. ve 3. sınıf düzeylerinde tekrar tanılama sınavlarına katılabilme ve destek eğitim programlarına yerleşebilme olanağı verilmesi şeklinde sıralanabilir.

Uzmanların büyük çoğunluğu (16: \%53) alınan ek önlemler sayesinde tanılama oturumlarında bazı istisnalar haricinde sorun yaşamadıklarını belirtmişlerdir. Uzman görüşlerinden bazıları kendi ifadeleriyle kesitler halinde aşağı da sunulmaktadır:

'Birinci sınıf düzeyi tanılamaya geçişin uzun ve sağllklı bir süreç sonunda gerçekleştirildiğini düşünüyorum. 2012 yılında uygulanacak yeni ölçeğin standardizasyon çalışmaları başladı. Uygulama da kullanışl, güncel ve düzeye uyumlu bir ölçek geliştirildi. Bu sayede tanılama sürecinde ciddiye alınacak oranda sorunla karşılaşmadım.' (U12)

'En önemlisi yeni sistemle ögrencilerimiz 2. ve 3. stnıfta da tekrar tanılama sürecine dâhil olabilmektedirler. Bu sayede sistem gözden kaçan öğrenci sayısını en aza indirmeyi planlamaktadır. Önümüzdeki yıllarda değişmezse aslında tanılama yaşı dörtten ikiye çekilmedi. 1., 2. ve 3. sinıfları kapsayan bir sürece dönüştürüldü.' (U6)

Diğer 14 uzman ise (\%47) yaşanılan sorunların yadsınamayacak kadar sıklıkta olduğunu belirtmişlerdir. Uzman görüşlerinden kendi ifadesiyle bir kesit aşağıda sunulmaktadır:

'Birinci sınıf öğrencileri çoğunlukla hayatında bir uzmanla görüşmemiş, bir sinava

katılmamış çocuklar. Çoğunlukla öğrenciye uygulama sırasında ne yapacağımızı hatta ne için burada olduğunu anlatmak bile çok zor oluyor.' (U14)

'Üçüncü sınıfta tanılamada bile öğrencilerin uygulama araçlarına uyumu açısından güçlükler yaşanabilmektedir. Bununla birlikte daha erken yaşlarda bireysel test aşamasında ögrenci tanılamak çok daha zor olmaktadır.(U22)

Uzmanların birinci sınıf düzeyi tanılama için belirttikleri başlıca dezavantajlar ise içerik analizi sonucu belirlenen anahtar kodlara göre aşağıdaki başlıklar kapsamında raporlanmıştır.

\section{Öğrencilerin Kendini İfade Etme Becerisi Açısından Yaşanan Güçlükler}

Uzmanların birinci sınıf düzeyi tanılamanın en çok (25: \%83) öğrencilerin düşündüklerini sözel olarak ifade etme becerisi açısından dezavantajlı olduğunu vurguladıkları görülmektedir. Buna göre uzmanlar, uygulama yaşı düştükçe öğrencilerin; cevap vermekte utangaçlık, kararsılılı, konuşmama isteği gibi davranış tepkilerini göstermeye daha eğilimli olduklarını gözlemlemişlerdir. Uzman görüşlerinden bazıları kendi ifadeleriyle kesitler halinde aşağıda sunulmaktadır:

'Her ne kadar uyguladı̆̆ımız bu yeni ölçeğe sözel olmayan bir ölçek diyorsak ta ögrrenci sizinle sözel olarak iletişim kurmadan uygulama yapmanı mümkün değildir ve süreç içinde bazen sözel dönütlerde de bulunmasi gerekmektedir. Birinci sınıf düzeyi ögrenciyi rahatlatıp kendini ifade etmesini sağlamak genelde daha zor olmaktadir.' (U18)

'Birinci sinıflar üçüncü sinıflara göre konuşmaya hatta ismini söylemeye bile isteksiz olabiliyor. Bu durumda öğrencinin de kaygllarını azaltıp uygulamaya odaklanmasını güçleştiriyor.' (U20)

\section{Duygusal ve Zihinsel Hazır bulunuşluk Açısından Yaşanan Güçlükler}

Uzmanların birinci sınıf düzeyi tanılamanın dezavantajlarına yönelik sıklıkla belirttikleri bir diğer durum ise (21: \%70) öğrencinin uygulamaya duygusal ve zihinsel yönden hazır hale gelmesi açısından yaşanan güçlüklerdir. Buna göre birinci sınıf düzeyi tanılamanın; öğrencilerin heyecan ve kaygı düzeylerini azaltmak, uygulamaya istekli ve kararlı hale getirmek, sürece odaklanmasını ve dikkatini vermesini sağlamak gibi hazır bulunuşluk tepkileri açısından dezavantajları yaşanabilmektedir. Uzman görüşlerinden bazıları kendi ifadeleriyle kesitler halinde aşağıda sunulmaktadır:

'1. sını ögrencilerini sürece hazırlamak genelde daha zor oluyor. Öğrenciyi sakinleştirmeniz gerekiyor. Hatta nadiren de olsa ağlama, korkma, annesine kaçma gibi tepkilerle karşılaştım. Dörtlerde böyle bir durumla hiç karşılaşmamıştım.' (U4)

'1. siniflarda hem duygusal hem de zihinsel olarak ögrenciyi oturuma hazır hale getirmek daha zahmetli olabiliyor.' (U12)

\section{Uygulama Süreci ve Yönergelerini Öğrencilerin Anlamasında Yaşanan Güçlükler}


Uzmanların birinci sınıf düzeyi tanılamanın dezavantajlarına yönelik en yüksek oranda belirttikleri bir diğer güçlük durumu ise (28: \%93) öğrencinin tanılama uygulamasını ve yönergelerini anlamakta yaşadıkları güçlükler olarak ortaya çıkmıştır. Uzman görüşlerinden birisi kendi ifadeleriyle bir kesit halinde aşağıda sunulmaktadır:

'Birinci sınıf düzeyindeki öğrencilerde genelde yönergeleri anlayana kadar daha çok tekrar etmemiz gerektiğini gözlemledim. Başlangıçta neler yapacağımızı da sabırla daha uzun ve detaylı anlatmamı gerekiyor.' (U15)

'Ü̧̧ aşamalı bir tanılama sürecine okul ile yeni tanışmış öğrencilerimizin uyum sağlamasını beklemenin hayalcilik olduğunu düşünüyorum. Ne kadar yetenekleri yaşıtlarına oranla üst düzey olursa olsun uygulamayı birinci sınıf ögrencileri ile başarılı bir şekilde tamamlamak çok zor olmaktadır.

\section{Uygulama Süresine Tahammül Açısından Yaşanan Güçlükler}

Uzmanların bir kısmının birinci sınıf düzeyi tanılamaya ilişkin belirttiği bir diğer dezavantaj ise (11: \%36) uygulamayı tamamlama süresi açısından yaşanan güçlüklerdir. Bazı öğrencilerde, başlangıçtaki motivasyonlarını kaybetmeleri, zihinsel olarak erken yorulmaları ve uygulamadan sıkılmaları gibi durumlar gözlemlenmiştir. Bu durumda yine öğrencin gelişim düzeyi ile ilişkili olarak açıklanabilir. Uzman görüşlerinden bazıları kendi ifadeleriyle kesitler halinde aşağıda sunulmaktadır:

'1. sınıflara başlangıçta tekrarla uygulamanın kesintisiz olacă̆ını, ara veremeyeceğimizi belirtmemize rağmen uygulama bitmeden çıkmak istemeler, serzenişler, tuvalete gitme istekleri gibi durumlarla karşılaşabiliyorsunuz.' (U14)

'1. sinıflar haliyle çabuk sıkılyyorlar. Bazen uygulamanın sonunu getirmekte daha çok zorlaniyorlar. Birkaç kerede oturum öğrencinin devam etmek istememesi nedeniyle başarlsız oldu.' (U25)

\section{Ülkemizde Üstüm Yeteneklilerin Tanılanmasında Kullanılan Araçların Uzman Görüşlerine Göre Genel Değerlendirilmesi}

Araştırmaya katılan uzmanlara özel yeteneklilerin tanılanmasında kullanılmaya başlanan yeni test araçlarının değerlendirilmesine ilişkin soru yöneltildiğinde ise; büyük çoğunlukla ve tüm sınıf düzeyleri için, sözel olmayan Weschler ölçeğinin ve ASISS Milli Zekâ ölçeğinin Wisc-R'a göre daha başarılı olduğuna inandıklarını ve beğendiklerini belirtmişlerdir (24: \%80). Ayrıca yeni ölçek daha önce belirtilen ek nitelikleri nedeniyle (kullanışlılık, kolaylık, açıklık vb.) 1. sınıf düzeyi için daha yararlı bulunmuştur (24: \%80).

Bununla birlikte bir kısım uzmanlar ise (11: \%37) sadece sözel yeteneklerin ölçümü açısından sözel olmayan Weschler ölçeğin sınırlılıklara sahip olduğunu belirtmişlerdir. 19 uzman ise (\%63) sözel yeteneklerin ölçülmesi açısından yeni ölçeğin herhangi bir sınırlılığı olduğunu düşünmemektedirler. Uzman görüşlerinden bazıları kendi ifadeleriyle kesitler halinde aşağıda sunulmaktadır:

'Sözel olmayan weschler ölçeğini ben daha başarılı buluyorum. Öncelikle çok daha güncel bir ölçek ve kolay uygulanabilirliği olan ölçekler. Wisc-R 1970'lerden kalma bir ölçekti. Böylece hem uygulama ölçeğimiz güncellendi hem de 1.ve 2. sinuf düzeyine göre daha uygun hale gelmiş oldu.' (U7)

'Yeni ölçekleri uygulamak çok kolay oluyor. Görseller üzerinden soruları yöneltiyoruz ve ögrenciler kolayllkla ilerliyor.' (U28)

'Wisc-R sözel yeteneklere ve sözcük dağarcığına daha dengeli yer veriyordu. Yeni ölçek düşünme becerilerini ölçüyor olabilir ancak sözlü ve yazılı anlatım becerilerini ölçmek açısından dezavantajlı oldu.' (U17)

Ayrıca uzmanların büyük çoğunluğu (27: \%90); ASİS Milli Zekâ ölçeğinin tamamen kendi kültürümüze ve toplumsal normlarımıza uygun olarak hazırlanmış olmasının önemli bir avantaj olduğunu belirtmişlerdir. Uzmanlar benzer şekilde ASİS ölçeğinin WISC-R'a oranla daha kolay ve kullanışlı olduğunu belirtmiş̧lerdir. Az sayıda uzman ise ASIS'in tekrar uygulanması durumunda öğrenme etkisinin görüldüğünü ve bilgiye dayalı kısımların azaltılarak yordama ve muhakeme gücüne dayalı içeriğin artırılması gerektiğini belirtmişlerdir. ASİS'e yönelik belirtilen bir başka olarak ise uzmanlar; ASİS'in diğer ölçeklere göre kolay olduğunu düşündüklerini ve bu durumun ölçme gücünde dezavantaj olabileceğini, zorlayıcılık düzeyinin artırılmasının yararlı olabileceğini belirtmişlerdir.

\section{TARTIŞMA SONUÇ ve ÖNERILLER}


$\mathrm{Bu}$ araştırma da ülkemizde ve dünyada tartışılan özel yeteneklilerin tanılanması için en uygun tanılama yaşının hangisi olduğu sorusuna yönelik sahada tanı ölçeklerini uygulayan uzmanların görüşlerine dayalı olarak değerlendirme yapılmaya çalışılmıştır. Araştırma bulgularına göre Rehberlik Araştırma Merkezlerinde Özel Yeteneklilerin tanılanması sürecini yürüten uzmanlardan tanılama yaşının 1. sınıf düzeyinden itibaren başlatılması kararının olumlu olduğunu düşünenler ve olumsuz olduğunu düşünenler birbirine çok yakın düzeydedir. Bununla birlikte içerik derinlemesine değerlendirildiğinde tanılama yaşıyla birlikte yeni uygulamaya koyulan tanılama araçlarını uzmanların beğendikleri gözlemlenmiştir. Bu durum özel eğitimin en temel ilkelerinden biri haline gelen 'erken tanı' ilkesiyle ve erken tanının etkisine yönelik alanda yapılmış olan geçmiş araştırmalarla da kısmen örtüşmektedir.

Ayrıca uzmanlar çoğunluk olarak ölçekte ve uygulama prosedürlerinde tanı yaşı düzeyine yönelik alınan ek önlemlerle 1. sınıf düzeyi tanılamanın dezavantajlarının kısmen kontrol altına alındığını düşünmektedirler. Bununla birlikte araştırma bulgularına dayalı olarak tanılama çalışmalarının ise 1. ve 2 . Sinıfla sinırlı tutulmaması ve sinırlılıklar göz önünde bulundurularak 3. Ve 4. sinıfta tanılama çalışmalarına da devam edilmesinin yararlı olacağına yönelik uzmanların hemfikir olduğu söylenebilir.

Araştırma bulgularına göre özel yeteneklilerin tanılanma yaşının düşürülmesinin beş farklı yönden katkısı olmuştur. Buna göre; öğrencilerin yetenek gelişimine, özel yetenekli öğrencilerin eğitsel beklentilerinin karşılanmasına, ebeveyn beklentilerinin karşılanmasına, yerleştirilen programın etkililiğine ve sanatsal yeteneklerin gelişimine tanılama yaşındaki esnekliğin yararları bulunmaktadır. Uzmanlara göre en çok sanatsal alanda özel yetenekli öğrencilerin keşfedilmesi ve erkenden yetenek alanlarında desteklenmesi için tanılama yaşının erken düzeylerde olmasının katkısı bulunmaktadır. Buradan yola çıkarak uzmanların görüşlerine göre sanatsal alanlara özgü tanılama çalışmalarının genel zihinsel yetenek tanılama çalışmalarından ayrı tutulması ve daha erken yaşlardan itibaren sanatsal yetenek alanlarına özgü tanılama çalışmalarının yürütülmesi gerekliliğinin olduğu sonucuna ulaşılabilir. Uzmanlar tanılama yaşının erken olmasının uygulanan programa katkısı konusunda ise oldukça sınırlı görüş belirtmişlerdir. $\mathrm{Bu}$ duruma gerekçe olarak genellikle uygulanan programla olan iletişimlerinin azlığını ve program çıktılarını gözlemleme olanaklarının olmadığını belirtmişlerdir. Araştırmadaki genel gözlemlere göre BİLSEM ve RAM arasındaki iletişim ve işbirliği eksikliği, hem tanılama çalışmalarının niteliği hem de uygulanan programın etkililiği açısından bir eksiklik olarak vurgulanmaktadır.

Araştırma bulgularına göre uzmanların büyük çoğunluğunun farklı değişkenler açısından erken yaşlarda tanılamanın bazı dezavantajlarını ve sınırlılıklarını belirttikleri görülmektedir. Genel olarak belirtilen güçlüklerin tanılama uygulamasının geçerliği ve güvenirliğine ilişkin olduğu görülmektedir. Bununla birlikte uzmanların yarıdan fazla bir kısmı, bu dezavantajların bazı ek önlemler ve uygun araçsal düzenlemelerle minimize edilmesi sonucunda, erken yaşta tanılamanın avantajların dezavantajlardan daha fazla olduğunu düşünmektedirler. Araştırma bulgularına göre tanılama yaşının düşürülmesinin dört farklı boyutta dezavantajları bulunmaktadır. Uzman görüşlerine göre; öğrencilerin kendini ifade etme yeterlilikleri açısından, öğrencilerin tanılama uygulamasına hazır bulunuşluk düzeyleri açısından, uygulama yönergelerini öğrencilerin anlaması açısından ve uygulama süresine öğrencinin tahammül düzeyi açısından erken yaş düzeyinde tanılama uygulamalarında güçlükler yaşanmaktadır.

Uzmanlar uygulama yaşı düştükçe öğrencilerin; cevap vermekte utangaçlık, kararsızlık, konuşmama isteği gibi davranış tepkilerini göstermeye daha eğilimli olduklarını gözlemlediklerini belirtmişleridir. Uzman görüşlerine göre; öğrencilerin heyecan ve kaygı düzeylerini azaltmak, uygulamaya istekli ve kararlı hale getirmek, sürece odaklanmalarını ve dikkatini vermelerini sağlamak gibi hazır bulunuşluk tepkileri açısından erken yaşlarda güçlükler yaşanabilmektedir. Uzmanlar en fazla olarak; öğrencilerin tanılama araçlarındaki uygulama yönergelerini anlamakta ve izlemekte sorunlar yaşadıklarını düşünmektedirler. $\mathrm{Bu}$ soruna çözüm olarak ise uzmanlar; tanılama araçlarındaki yönergelerin erken yaş düzeyi için basitleştirilmesi, ayrıntılandırılması ve azaltılması gibi önlemlerin uygulanabileceğini belirtmektedirler. Ayrıca eğer mümkünse yeni milli zekâ ölçeğinin farklı sınıf ve yaş düzeyleri için farklı versiyonlarının geliştirilebilmesinin yararlı olacağı uzmanlar tarafından belirtilmiştir.

Uzmanların büyük çoğunluğuna göre yeni uygulamaya giren yerli ve milli zekâ ölçeklerinin ise ülkemizde özel yeteneklilerin tanılanması sürecinin başarısını artırdığı ve uygulama kolaylığı sağladığı düşünülmektedir. Uzmanların ASİS ölçeğine yönelik tekrarlayan uygulamada öğrenme etkisinin azaltılabilmesinin yararlı olacağını belirtmişleridir. Ayrıca görüşü alınan uzmanların bir kısmı ASİS ölçeğinin Uzmanların tanılama yaşının BİLSEM'lerde yürütülen program üzerindeki etkileri konusunda ise yeterli deneyim ve gözleme sahip olmadıkları görülmüştür. Bu durum Sak ve arkadaşları (2015) tarafından yapılan ve tanılama ölçekleri ile uygulanan program arasında uyumsuzluk olduğunu belirten 
araştırma bulguları ile de örtüşmektedir. Buna göre RAM uzmanları ile BİLSEM programının yürütücüleri arasında işbirliği ve iletişim eksikliğinden söz edilebilir.

$\mathrm{Bu}$ çalışmanın sonuçlarına göre tanılama sürecini yürüten uzmanlardan tanılama yaşının erkene çekilmesi kararının olumlu olduğunu düşünenler ile olumsuz olduğunu düşünenler birbirine yakın düzeydedir. Uzmanlar tanılama yaşının erken olmasının birçok avantajını ve yararını belirtmekle birlikte tanılama sürecinde yaşanan bazı güçlükler ve sınırlılıklara ilişkin de görüşler belirtmişlerdir. Uzmanların çoğunluğu yapılan ek düzenlemelerle birlikte erken yaşta tanılamanın avantajlarının dezavantajlardan daha fazla olduğunu düşünmektedirler.

Bu çalışma öğrenciler, ebeveynler ve öğretmenler gibi sürece dâhil olan diğer paydaşlarla daha geniş kapsamlı olarak araştırılabilir. Program çıktılarını değerlendirecek kadar yeterli uygulama süresine ulaşıldıktan sonra, durum çalışması, tarama vb. yöntemlerle, tanılama yaşının etkileri öğrenci performansı gibi nicel verilere dayalı olarak ta sinanabilir. Tanılama uzmanları ile program uygulayıcıları arasında iletişim ve işbirliğini geliştirmeye yönelik çalışmalar yapılabilir. Bilsem uzmanları tanılama geliştirme/iyileştirme çalışmaları sürecine daha fazla katkı da bulunması sağlanabilir. Tanılamada yapılan değişikliklerin uygulamaya ve öğrenci başarısına etkileri deneysel yöntemlerle araştırılarak geri bildirim alınabilir.

\section{KAYNAKÇA}

Ataman, A. (2004). Üstün zekâll ve üstün yetenekli çocuklar. Üstün yetenekli çocuklar seçilmiş makaleler kitabı. Haz: M. R. Şirin, A. Kulaksızoğlu ve A. E. Bilgili. İstanbul: Çocuk Vakfi Yayınları.

Baykoç,N. (2014), Özel Gereksinimli Çocuklar ve Özel Eğitim, Ankara: Pegem Yayıncılık

Büyüköztürk, Ş., Kılıç Çakmak, E., Akgün, Ö.E., Karadeniz, Ş. ve Demirel, F. (2010). Bilimsel Araştırma Yöntemleri (6.baskı). Ankara: Pegem Yayınları

Clark, B. (1997). Growingupgifted (5. Bask1). Upper Saddle Hill, New Jersey: Prentice-Hall, Inc.

Eker, A., Sarı, H., Kurnaz, A. (2018). Üstün Yeteneklilerin Tanılanması Süreci, Üstün Yetenekliler ve Tanılama içinde, (Ed. Uğur SAK). Vize Yayıncılık, ANKARA.

Heller, K. A.,Schofield, N. J. (2008). Identificationand Nurturing the Gifted from International perspective. S. I. Preiffer (Ed), Hanbook of giftedness in children (93-114). New York: Springer.

Kuş, E. (2009). Nvivo 8 İle Nitel Araştırma Projeleri. Ankara: Anı Yayıncılık.

MEB (Milli Eğitim Bakanlı̆̆ı) (2018), Özel Eğitim Hakkında Kanun Hükmünde Kararname ve Özel Eğitim Hizmetleri Yönetmeliği. Ankara: Milli Eğitim Basımevi

Moore, A. D. (1992). Gifted and talented children and youth.(ed. L. M. Bullock). Exceptionalities in Children and Youth. USA: Allynand Bacon Inc. s. 420-448

Sarı, H. (2003), Özel Eğitime Muhtaç Öğrencilerin Eğitimleriyle İlgili Öneriler, Ankara: Pegem Yayınları

Seçer, Z. ve Sarı, H. (2006). Okul öncesi eğitim kurumuna devam eden ve etmeyen çocukların ahlaki ve sosyal kural bilgilerinin çeşitli değişkenler açısından karşılaştırmalı olarak analizi. Milli Eğitim Dergisi,172, 126-142.

Sak, U. (2012). Üstün zekâlılar: tanılanması, özellikleri, eğitimi, Ankara: Maya Akademi

Sak, U., Bal Sezerel, B., Ayas, B., Öpengin, E., Özdemir, N., Demirel Gürbüz, Ş. (2015). Türkiye'de Üstün Yeteneklilerin Eğitiminin Eleştirel Bir Değerlendirmesi. Türk Üstün Zekâ ve Eğitim Dergisi 5(2), 110132-.

Tucker, B., Hafenstein, N. (1997). Psychological intensities in young gifted children. Gifted Child Quarterly, 41 (3), 66-75.

Yıldırım, A. ve Şimşek, H. (2005), Sosyal Bilimlerde Nitel Araştırma Yöntemleri, Ankara: Seçkin Yayıncılık. 